\title{
Coordinating Mind and Body: A Comparison of Three Somatic Approaches for Improving Wellness and Performance of Pianists
}

\author{
Yuanchang Zhou \\ School of Music and Dance, Nantong Normal College, Nantong 226010, Jiangsu, China \\ Email: 3443006503@qq.com
}

\begin{abstract}
Among all barriers to a professional pianist's performance, hand injuries can be the most traumatic. Chronic pain and other debilitating problems can cause not only physical suffering, but severe and emotional turmoil. When discouraged by countless cancellations due to physical problems, many pianists consider themselves failures. Throughout history, celebrated pianists such as Robert Schumann, Alexander Scriabin, Gary Graffman, Leon Fleisher, and Glenn Gould fell victim to hand injuries, in some cases even causing permanent damage that sidelined, or even terminated, their performing careers. Often traditional medicine is not the most ideal solution for effectively curing a pianist's hand injuries, as most problems are more likely related to improper movement and use of the body while playing. The purpose of this essay is to introduce three effective somatic approaches to piano playing, offering not only possibilities for the treatment of physical problems, but also preventive methods in obtaining a pain-free experience for performing pianists.
\end{abstract}

Keywords: Dorothy Taubman, Barbara Lister-Sink, Alan Fraser, somatic approach

\section{Introduction}

Among all barriers to a professional pianist's performance, hand injuries can be the most traumatic. Chronic pain and other debilitating problems can not only cause physical suffering, but severe and emotional turmoil as well. When discouraged by countless cancellations due to physical problems, many pianists consider themselves failures. Throughout history, celebrated pianists such as Robert Schumann, Alexander Scriabin, Gary Graffman, Leon Fleisher, and Glenn Gould fell victim to hand injuries, in some cases even causing permanent damage that sidelined, or even terminated, their performing careers.

Robert Schumann (1810-1856) sustained irreparable damage to his right hand after using a "mechanical device" to strengthen his fourth finger to make it stronger and more independent. Medical treatments at the time, which included "animal baths" (immersing the affected part of the body in a dead animal, the blood and body fluids were believed to have curative powers), herbal bandages, and electrical stimulation had little to offer. Schumann visited doctors in cities such as Leipzig, Dresden, and Schneeberg but with no results. Some contemporary pianists, such as Leon Fleisher (b. 1928), have faced similar situations with physical maladies, which were not initially understood by physicians. In Fleisher's case, he experienced a "curling of the fourth and fifth fingers under the palm" of his right hand (not due to faulty playing). After being subjected to psychiatric treatment, acupuncture, hypnosis, and deep-tissue massage, he was found to have a condition now known as focal dystonia. Fleisher noted that he "was simply floundering" due to the lack of adequate medical understanding about his condition. Fleisher was eventually able to continue his career with left-hand repertoire, teaching, and conducting, eventually making a return to two-handed playing. For any performing artist, the frustration and depression brought on by such impairment compounds the music career to an even greater degree.

Traditional medicine is not often the most ideal solution for effectively curing a pianist's hand injuries, as most problems are more likely related to improper movement and use of the body while playing. The purpose of this essay is to introduce three effective somatic approaches to piano playing, offering not only possibilities for the treatment of physical problems, but also preventive methods to help in obtaining a pain-free experience for performing pianists.

\section{Somatic approaches}

What is a somatic approach? For the purposes of this essay, it is defined as:

Somatics is a path, a methodology, a change theory, by which we can embody transformation, individually and collectively. Embodied transformation is foundational change that shows in our actions, ways of being, relating, and perceiving... Somatics pragmatically supports our values and actions becoming aligned. It helps us to develop depth and the capacity to feel ourselves, each other and life around us. 
Somatics builds in us the ability to act from strategy and empathy, and teaches us to be able to assess conditions and "what is" clearly. Somatics is a practice-able theory of change that can move us toward individual, community and collective liberation. Somatics works through the body, engaging us in our thinking, emotions, commitments, vision and action.

Throughout history, somatic approaches to health have appeared in various forms, from dance to martial arts, psychotherapy to spiritual practice. The uniqueness and healing power of these approaches explain their prominence and popularity in industrialized societies today. For example, the growing interest in yoga and meditation practice, the burgeoning of Buddhist meditation in Western countries, and the rapid development of chiropractic and naturopathic medicine all reflect people's tendencies to seek a healthier lifestyle other than that offered by traditional methods.

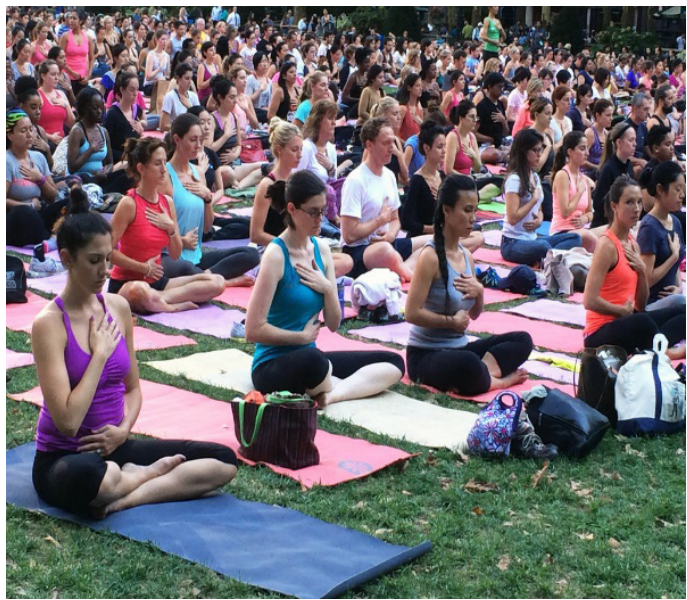

Figure 1. People taking a free yoga class in Bryant Park, New York

The word "somatic(s)" originates from the word "soma", meaning "the body as perceived from within". In a conversation between Helmut Milz, M.D. and Thomas Hanna, the creator of the word, Hanna defined somatics as a culture that "has respect for the given genetic potentialities of the human being in general and the human individual in particular". It is a "living process" that enables human beings to freely develop, explore, and discover their potential and that cultivates our consciousness to be better self-guided and poised in life. "Freedom is essentially self-responsibility and independence," said Hanna.

To differentiate traditional medicine from the somatic ways of achieving health and wellness, traditional medicine separates the mind and body whereas somatic ways combine the two. During a typical medical treatment by conventional medicine, the diseases/problems are usually treated by drugs or surgery. The "mind" is not engaged to interact with the body during the treatment, while the "body," where the problem exists, is accepting external assistance (from the medicine, for example). Traditional approaches often just treat the symptom rather than the cause. Even though clinical tests have shown traditional medicine's success for numerous diseases, movement-related issues require a consistent interaction between mind and body; for problems commonly encountered by pianists, traditional medicine can be of partial help. (It is worth mentioning here that "mind" refers to the sensory-motor aspect of our brains, which receives and generates external messages every day and then produces responses based on our own experiences and long-formed thinking patterns.)

Hans Seyle (1907-1982), one of the twentieth century's most recognized figures in medical research, was the first to reveal the relationship between physiological diseases and biological stress, and that "physiological diseases could rise from psychological causes, such as stress." Daily stresses and traumas result in a series of unconscious responses from our sensory-motor system, and affect muscular reflexes from the stimuli that might become habitual patterns. This process damages our sensory-motor apparatus, which triggers kinesthetic memory loss, and we no longer recall how certain muscles move and how we used to respond to those stimuli, such as an unexpected sound or noise. Thus, stiffness and soreness occur in our bodies, limiting the range of movements. This muscular memory loss (termed by Thomas Hanna sensory-motor amnesia, or SMA) facilitates the formation of uncoordinated movements and stimulates compulsive behaviors. The internal resistance that accompanies these behaviors separates our mind and body while creating a "conflicting pattern," which prevents us from attaining bodily coordination. Additionally, Selye mentioned the existence of "diseases of adaptation," which link body diseases with a failure of mind-body cooperation and adaptation to the circumstance, and he named this condition general adaptation syndrome (GAS). He said:

Life is largely a process of adaptation to circumstances in which we exist... The secret of health and 
happiness lies in successful adjustment to the ever-changing conditions on this globe; the penalties for failure in this great process of adaptation are disease and unhappiness.

Hanna agreed with this statement, finding a connection between Selye's philosophy and the somatic standpoint because they both view psychological events as one of the direct causes for human diseases. People must eliminate the contradictions between the mind and body to live a healthy life. By emphasizing the coordination of mind and body, we look from the inside-out and are aware of the feeling of the body instead of just the body itself. By properly adjusting, we can take control of our lives.

Without a doubt, SMA, which is one of the major causes of movement problems, belongs to the category of "diseases of adaptation." As "SMA is an adaptive response of the nervous system... it is a learned adaptive response. Therefore, it can be unlearned.

\section{Background, origin and purpose of the three somatic approaches}

\subsection{Alan Fraser and The Craft of Piano Playing}

Alan Fraser wrote The Craft of Piano Playing in 2003, a method that combines piano technique with the Feldenkrais Method. It was created by the Israeli physicist and martial arts practitioner, Moshé Feldenkrais. Fraser described himself as an "uneducated youngster" at an earlier age, but also as a talented musician with "intelligent ears." Sensing that Canadian pianist and pedagogue Phil Cohen could be the one at that time who could help him, Fraser started following Cohen's path and delved into the world of psycho-physics.

Cohen was an advocate of psycho-physics, and he "... developed a way of teaching the movements of the hand and arm to translate into exact gestures that 'sculpted' phrase shape and emotional expression." Inspired by Leonardo da Vinci's perfect combination of emotional expression, anatomy, and mathematics in his paintings, Cohen founded the Leonardo Research Project to investigate such connections for musicians. Immediately attracted by Cohen's style, Fraser spent several years studying with Cohen's students. Upon hearing a recital by Cohen's student Kemal Gekich, Fraser noted:

He displayed all the technical qualities I had been looking for. Physically reposed, almost meditative in his stillness, but with an aware attention that watched fingers, hands and arms spraying out swathes of brilliant passagework, singing cantabile, stirring drama and exquisite poetry.

Truly inspired by this performance, Fraser finally settled down to study with Gekich to further develop his playing.

While studying with Gekich, Fraser also encountered the Feldenkrais Method, the somatic method that connects the mind with the body, and educates the body to generate vital and efficient movements. The method shares the same foundation with Cohen's teaching, and both of them employ the study of bio-mechanics.

\subsection{Dorothy Taubman and the Taubman Approach}

Different from the Craft of Piano Playing, which uses a whole-body method as the dominant component to approach the piano, the Taubman Approach concentrates mainly on the playing apparatus (the arms and hands).

Many gifted young piano prodigies were lost in the "transition from intuitive to conscious playing." This unfortunate fact, which was caused by a lack of awareness-training in piano playing, greatly limited the potential of these pianists' musical careers. Therefore, Dorothy Taubman developed an entire system of education to “...uncover the secrets of virtuoso technique to assist gifted pianists in realizing their potential." This approach of developing consciousness acts as the solid foundation for supporting young talents.

As an educator, Taubman first underestimated her own discovery, thinking that "everyone knew about the technique but me." By helping many pianists successfully overcome their technical limitations, Taubman gained a positive reputation in the US and developed from an "underground teacher" who taught privately to a respected piano pedagogue who gave public masterclasses. Her way of teaching evolved to a systematic approach for mind/hand/arm coordination, now called the Taubman Approach.

In 2003, Taubman's students Edna Golandsky, John Bloomfield, Robert Durso, and Mary Moran founded the Golandsky Institute to build a broader platform for Taubman's work. The Golandsky Institute holds annual symposiums at Princeton University and provides training programs and workshops for those piano teachers who are interested in becoming Taubman instructors. Today, there are more and more people becoming Taubman teachers; the Taubman Approach has expanded extensively, with teachers in Asia, Europe, and North America. Taubman passed away in 2013, and her contributions to the piano field are still benefitting pianists of all ages and levels. 


\subsection{Barbara Lister-Sink and Freeing the Caged Bird}

Being injured herself at a young age, Barbara Lister-Sink suffered from tendinitis. The subsequent discomfort in playing impeded her growth as a pianist and brought her to study with Edith Grosz, an American piano pedagogue based in Amsterdam. Grosz's teaching focused on cultivating "careful awareness of the musculoskeletal system." It successfully cured Lister-Sink's injuries and catalyzed the formation of Freeing the Caged Bird.

Similar to The Craft of Piano Playing, the Freeing the Caged Bird method also combines a whole-body approach with the Alexander Technique. Since the Alexander Technique is limited in its applications for piano playing, it is better taught prior to coordinating the hands using the Basic Stroke (see Lister-Sink p.34) in order to first develop one's kinesthetic awareness. In addition to its appropriation of the Alexander Technique, Freeing the Caged Bird was also influenced by the Feldenkrais Method, the Taubman Approach, and other methods. Lister-Sink requires students to have a concurrent study on the field of cognitive embodiment and training with a certified Alexander Technique instructor while learning the method.

\section{Discussion of the three somatic approaches}

\subsection{Alan Fraser: The Craft of Piano Playing}

\subsubsection{The overview}

In recent history, the Feldenkrais Method was applied to piano playing by Alan Fraser. As one of the leading figures in the field of somatics, Moshé Pinchas Feldenkrais brought attention to mind-body coordination to improve both body movement and psychological states. He was convinced that every human being has a wide range of potentialities. The Feldenkrais Method aims at unleashing these potentialities, starting from enhancing awareness in the brain (or nervous system), coordinating the body to function in harmony, and then adjusting to the various environmental and specific personal experiences. Being inspired by different events leading to the creation of his method, Feldenkrais was originally influenced by the psychology of Judo (gentle way), which emphasizes the efficiency and vitality of movements. It is the manipulation of body movements for a purposeful attack and result. A Judo master gave an analogy between Judo and water, and he said:

... the principle of Judo is like the nature of water. Water flows to a balanced level. It has no shape of its own but molds itself to the receptacle that contains it. It has existed and will exist as long as time and space exist. When heated to the state of steam it is invisible, but has enough power to split the earth itself. When frozen it crystallizes into a mighty rock. Its services are boundless and its uses endless...

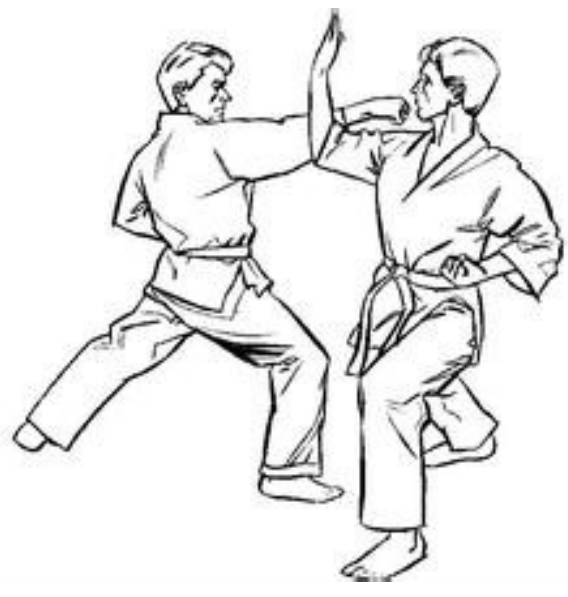

(a)

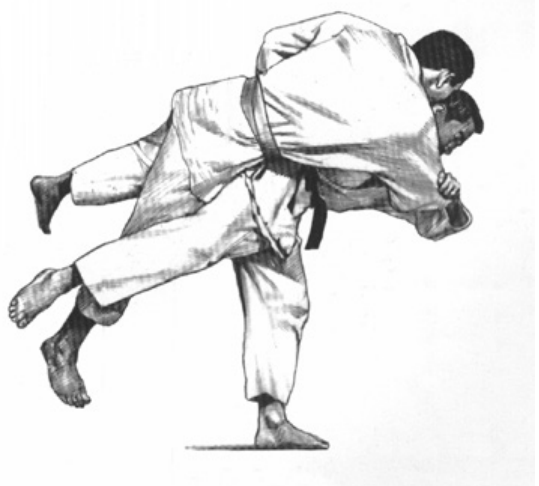

(b)

Figure 2. Judo positions

Water is a good analogy for being able to adapt to various circumstances, a duality of both gentleness and power, of peace and turbulence, implying the continuous flow of life. Feldenkrais applies the analogy of water and the psychology of Judo into his method, working closely to achieve coordination of body and mind.

Feldenkrais Method's classes are taught in two segments. (1) Awareness Through Movement (ATM). (2) Functional Integration (FI). In an ATM class, the teacher verbally directs movement sequences to a group of students, while allowing freedom for everyone to feel and explore the new concepts for themselves. The FI class is a one-on-one private lesson 
setting. Here, individual habitual patterns are identified and the instructor works with the student to improve body function and eliminate problems.

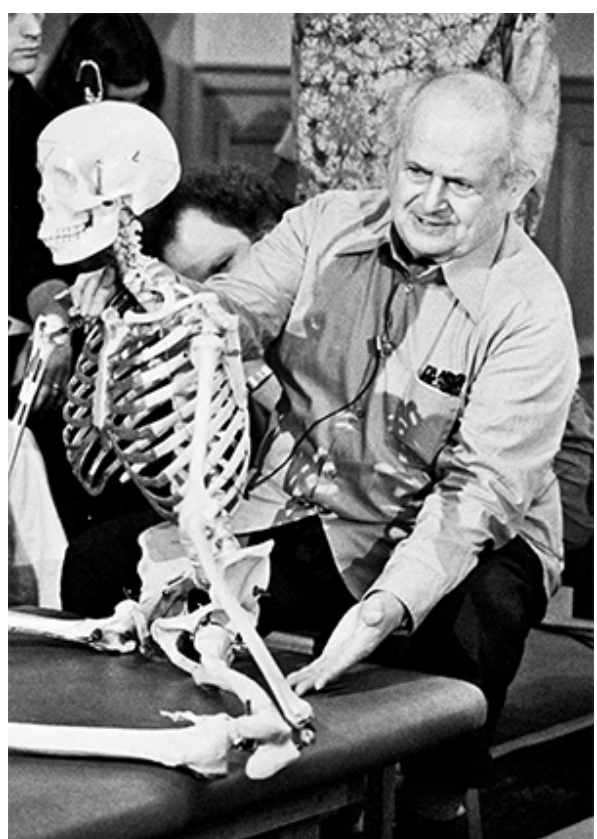

Figure 3. Moshé Pinchas Feldenkrais illustrating the function of human skeleton in sitting.

Fraser integrated Feldenkrais's two classes (ATM and FI) into a single, hands-on form. His mission is to apply Feldenkrais's philosophies, emphasizing the association of physical sensation with perfection of sound and using this scientific analysis as a bridge to connect the mind with the body.

The concept of "understanding before acting" plays an important role. In a Feldenkrais piano lesson, Fraser explains the pros and cons of what the pianist's next posture or movement may be. By successfully predicting, and then exposing the cause and effect of a yet-unperformed movement, students can make their own preconceived movements to avoid potential risks. There are three principles Fraser wants students to grasp.

(1) A stable hand structure (the arch):

The ideal hand structure here is the shape of an "arch." The knuckles are raised high like a "mountain top," and the fingers naturally drop down from the "mountain," forming a half-rounded shape (Figure 4).

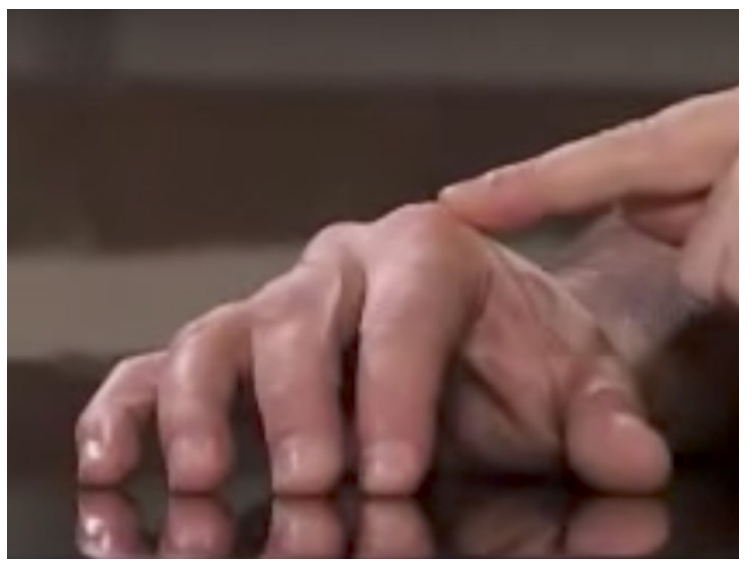

Figure 4. The Craft of Piano

The hand structure should be stable, not fixed. Fraser wants movement to be continuous and dynamic, creating flexibility to suit the music's needs and make the music vital. In a good arch shape, the upper arm of the hand must remain stable, and the fingers should feel like they "drop into the keys" from this "platform" (upper part). With this natural dropping, fingers can flex and extend within the arch structure easily. This kind of "changing dynamic" prevents strain and tension in hands. Taking Debussy's Brouillards: Modéré from his Préludes Book II as an example, we encounter three 


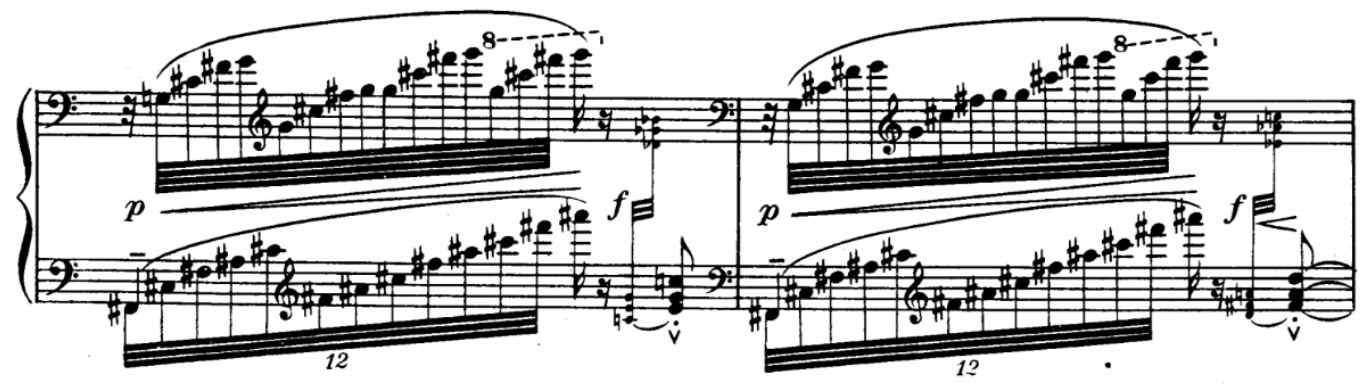

Figure 5. Claude Debussy, Brouillards: Modéré, from Préludes Book II, mm. 29-30

It is important here not to press the keys, instead, let the fingers flex and extend to the arch structure after the sounds are made. During playing, Fraser always wants a connection between the body and an inner gesture from the heart, and the body is expected to act according to the inner gesture. A genuine expression of the inner gesture enables the connection between mind and body.

(2) Aligned skeletal structure:

"The more correct the alignment of your skeletal structure, the less effort needed to carry out an action effectively." Reduced muscle work can maximize not only the function of the body, but pianists' sensitivity is also sharpened to feel and control the sound. A good structural alignment can improve their wellness and their music making. In addition, a good skeletal alignment can prevent this sequence: over-moving--over-relaxation--over-tension, the inevitable occurrence and painful result that pianists encounter when acting under an unstructured skeleton, being operated by intuition and old habits.

A paragraph from Fraser's book The Craft of Piano Playing can well interpret an ideal hand structure:

The assembly of bones must be neutral not stiff, yet so well organized that all the tremendous stress exerted on it doesn't distort its structure. Great power can now be transmitted through your hand, but because it is structurally secure, there is no cramping and damping of the sound...

(3) The accuracy in the contraction of muscles and exactitude of muscle activity:

To avoid a harsh or an unexpectedly muted sound, it is important to know how much effort the body will use to produce the sound. A lack of accuracy and exactitude will result in "jamming" and "convulsions" (from overreacting) or oppositely, the muted sound (from inadequacy). Moreover, a wrong muscle contraction breaks the alignment of the skeleton by inhibiting the natural process of movement, and the convulsions disturb the music making, which results in the music sounding forced and intense. Fraser suggests imaging that the piano key is "slowing down" to ease away the force; also, "practicing ff passages mp or even pp" so that there is space and a better sensitivity to "bring convulsion into awareness."

\subsubsection{The uniqueness}

Fraser's use of terminology corresponds scientifically with the Taubman and Lister-Sink approaches. The Craft of Piano Playing combines science with music and incorporates Feldenkrais's teaching language, which integrates with an anatomical analysis of the human body. The logical aspect of the method is well-reflected in Fraser's detailed description of the structure of the hand and how every bone functions as an important part for generating movement:

The three bones of each finger are the distal (furthest), medial (middle), and proximal (closest) phalanges.

The four bones of the hand that join your fingers to your wrist are called the metacarpals...the knuckle where your finger joins your hand is the metacarpal-phalangeal joint... The deep flexor (sometimes called the long flexor), located in the forearm, curls the finger by pulling on its very tip, the distal phalange. The superficial flexor (sometimes called the short flexor), also located in the forearm, curls the finger by pulling on its middle, the medial phalange. The lumbrical, located immediately around the metacarpalphalangeal joint, pulls on the proximal phalange, drawing the whole finger as a single unit towards the palm without bending it. The wrist is a clever arrangement of eight bones, a double hinge joint that moves most easily in the plane that is vertical when our hand lies flat...

The most ideal hand shape in The Craft of Piano Playing consists of a potent and stable arch, with the second metacarpal phalange (the one affixed to the index finger) standing the highest of all five. To illustrate this natural arch 
shape, Fraser used a string, which was attached to the metacarpal-phalangeal joints of the hand. He slowly pulled the string up and down to allow the hand to passively follow the direction of the string in order to display the most natural shape of the hand. When the bones are well-aligned in the natural arch with every bone raised, the hand is now considered powerful and potent. In the DVD of The Craft of Piano Playing, Fraser linked the hand arch to the vaulted cathedral ceiling, with the four metacarpal phalanges mirroring the four-ribs of the vault (as shown in Figure 6 and 7). This analogy adds a sense of the sublime and the divine to this simple, yet fundamental hand shape.

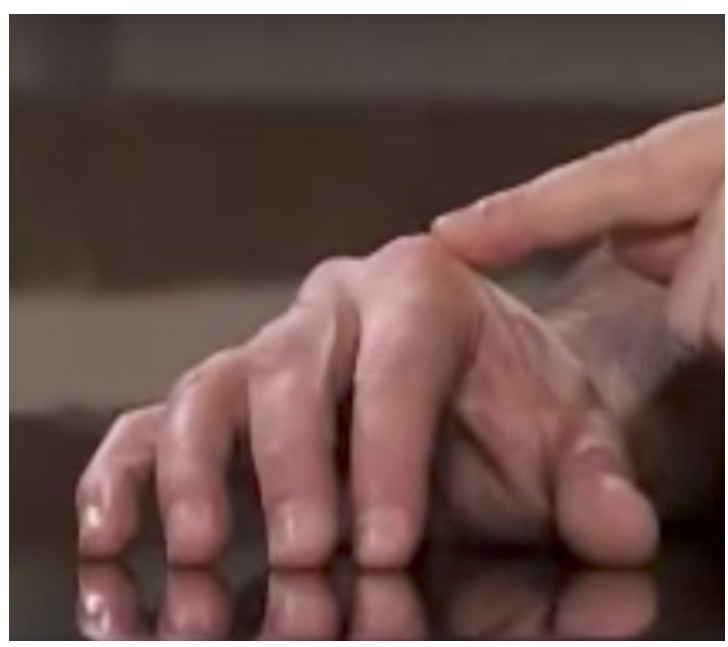

Figure 6. The Craft of Piano Playing

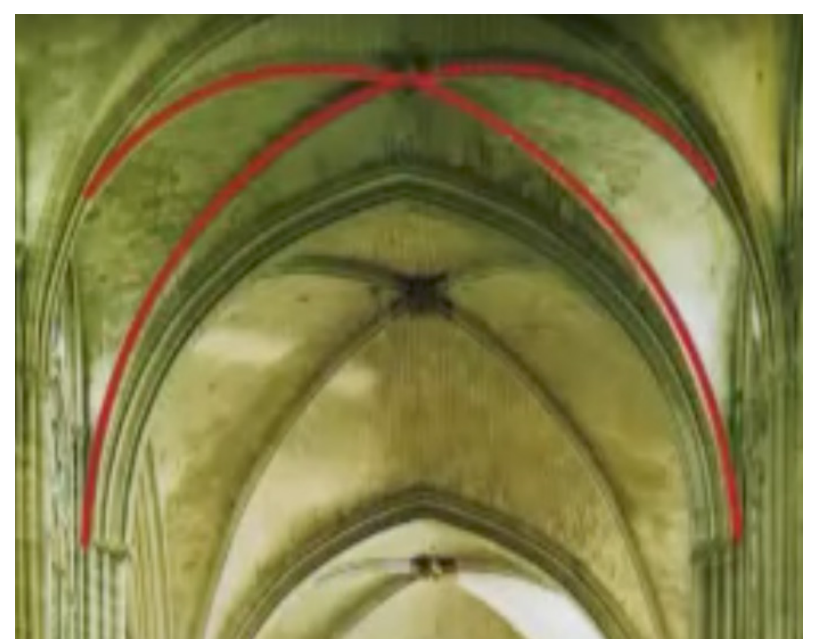

Figure 7. The vaulted cathedral ceiling

\subsubsection{From stability to movability}

According to Fraser, there are two steps for achieving optimal piano playing. To "develop the stability of the skeletal alignment" is the first but not the foremost step; it is equally crucial to "develop the functionality, its ability to move: suffuse that structure with life, with action."

An effective hand activity is the result of structural integrity, and vice versa. The structural integrity means a functional body structure, made possible by a good alignment of the bones. As mentioned earlier, an ideal bone alignment is "neutral not stiff," but it is "so well organized that all the tremendous stress exerted on it doesn't distort [it]." Moreover, it allows "great power to be transmitted through your hand, but because it is structurally secure, there is no cramping and damping of the sound." It is the cooperation of all the structural components of the hand that assures effective activity and mobility. The fingers play an important role in activating this structure.

\subsubsection{Arm or finger?}

There is an age-old debate between the "arm weight" and "finger action" schools. The former advocates the arm's responsibility for producing beautiful sound while the latter relies on the fingers' power to make the sound. The former thus supports fingers' relaxation, and the weight is transferred from the shoulder to fingers. On the opposite, the latter agrees on 
the fingers' own ability, separating the fingers from the arm and shoulder to make sound.

Fraser believes that a beautiful tone being only obtainable by arm weight is a misconception, because an uncontrolled sound is "dead." Under total relaxation, "reduced activity in your hand weakens its structure...", then "muscular contractions" compensate for a collapsed structure and also inhibit movement. However, total finger action is also incorrect because finger activity without support of the rest of the body does not have a potent structure. Not only will the separated hand parts, along with the unsupported fingers, destroy the natural hand structure, the finger muscles will also become stressed for "fighting alone." As a result, both approaches will lead to hand injury.

Fraser thinks that the ideal way for producing a good piano tone is to "maintain optimum balance between relaxation and activity."

It is true that they must not be inhibited by an overly tense muscle tonus. But it is equally true that too much relaxation renders your playing ineffectual--your muscles simply do not move enough to do their job!

Fraser thinks that piano playing must rely on muscular activity; without active muscular movement, there is no life. When the bones are well-aligned, affecting a potent structure with organized movements within, the music is then given momentum and life.

\subsubsection{3 "Grasping" as the first step}

When the fingers move, it is either to "flex or extend, abduct or adduct." This forms the movement known as grasping. Fraser considers it as the fundamental technique in piano playing and basic finger-movement to activate the arch and the structure.

Grasping is the intrinsic ability every human being naturally possesses. When grasping, the lumbrical muscles located around the metacarpal-phalangeal joint play an important role to activate the movement, making the fingers powerful. Furthermore, this movement coordinates well with the natural construction of the hand, so that it prevents muscles from pulling against each other, which usually results in hand injuries. When all fingers are grasped towards the middle of the palm, the arch displays the most potent and powerful shape (see Figure 8 and 9).

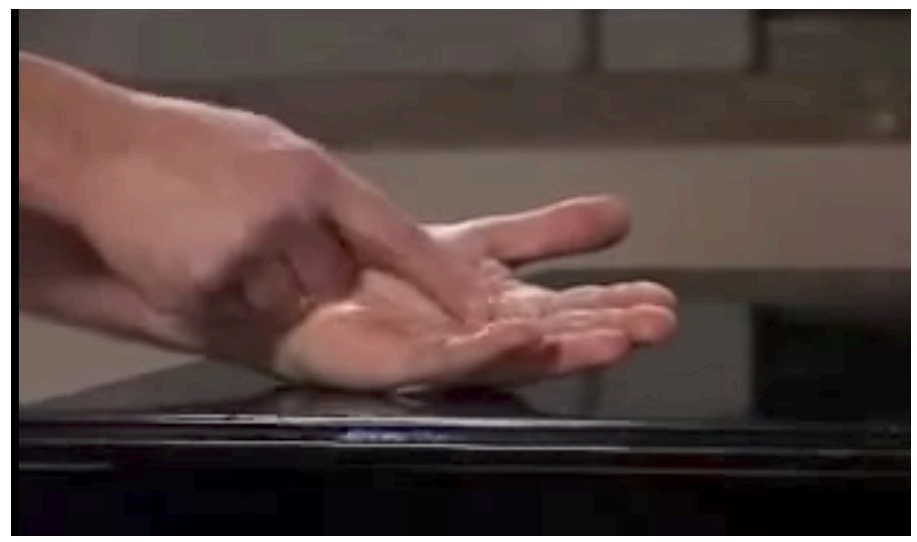

Figure 8. Fingers grasping towards the center of the palm

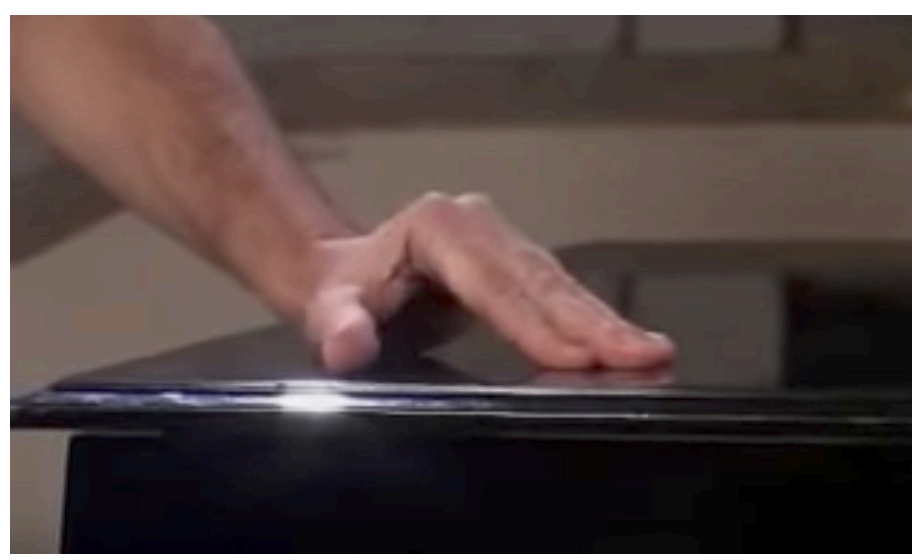

Figure 9. The potent arch structure made possible by capable grasping 


\subsubsection{Thumb push-ups}

In grasping, the thumb cooperates with the other four fingers to display the hand's natural strength by pulling the muscles inward to the palm. The way of transferring the grasping of the thumb to a functional motion is through exercises of thumb push-ups. Fraser created exercises to train the thumb strength and maximize its power:

Put your thumb on a key; then, 'standing' on it, stretch your four fingers, lifting them as high as you can. Point them to the ceiling, all the while letting a considerable, even close to unbearable amount of weight press down through the thumb into the key. Here the continuous pressure of your arm exerted on your thumb and hand imitates the weight of your body on your hands and arms in real pushups.

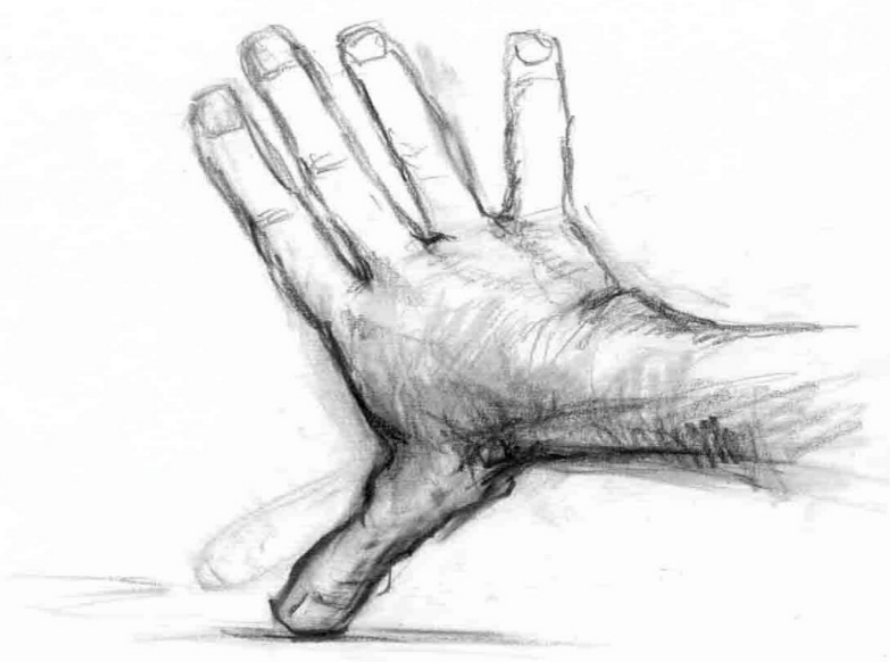

Figure 10. Thumb push-up in the Craft of Piano Playing

\subsubsection{Legato}

The legato playing in The Craft of Piano Playing resembles the Tai Chi walking. Legato is also a good example of how fingers maintain strength during the note-to-note playing. The weight transfer from finger to finger is like the walking feet of Tai Chi, when the left foot transfers the weight to the right foot. The legato is felt at the metacarpal-phalangeal joints, not only at the finger tips. When playing, there is a split second of both keys being pressed down at the same time, similar to using the pedal.

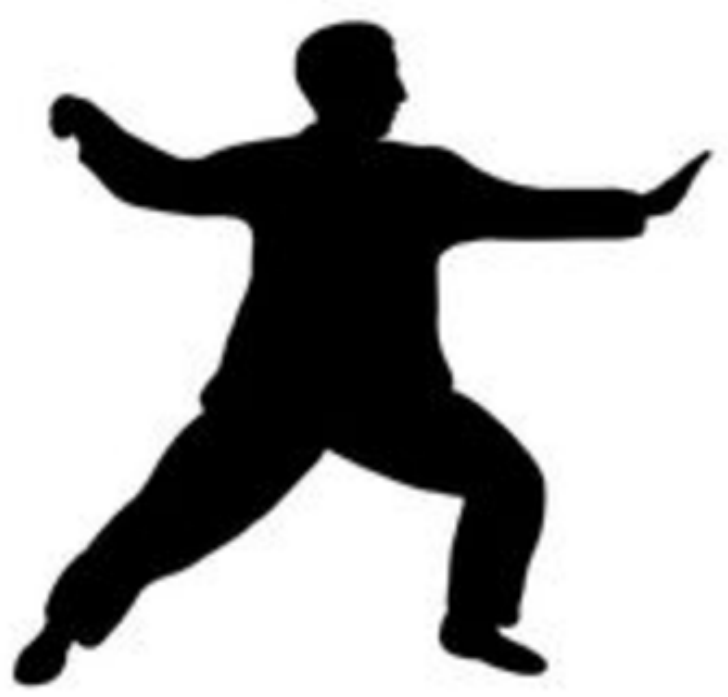

Figure 11. Tai Chi walking 


\subsection{The Taubman Approach}

\subsubsection{The overview}

The Taubman Approach was created by Dorothy Taubman (1917-2013). This somatic method is "a comprehensive approach to piano technique that allows for an ordered and rational means of solving technical problems." Taubman believed that most pianists' injuries are playing-related and curable if "we know the right way to do it." And that if playingrelated problems are not addressed right away, they can only lead to further problems.

Based on Taubman's research, the major causes of tension/hand injuries originate from "curling, isolating the fingers, twisting, key-bedding, stretching, and a low wrist." Injuries, such as tendonitis or PRMD (performance-related musculoskeletal disorders), are some of the inevitable consequences of these faulty approaches to playing. To prevent injuries from happening, Taubman developed a series of techniques, collectively constituting a systematic approach for pianists to achieve a "healthy virtuosity". In her dissertation, Learning and Teaching Healthy Piano Technique Training as an Instructor in the Taubman Approach, Therese Elaine Milanovic maintains that optimal piano playing is the "desirable marriage of healthy pianistic practice and virtuosity...[it] incorporate(s) comfort, but also power, brilliance, ease, freedom, control and speed."

The basic rules in the Taubman Approach involve the alignment of finger, hand, and arm to form a cooperative, dynamic relationship. The ideal hand position/alignment is the natural shape of the hand, when we let the hand hang at the side of the body. When in motion, this hand shape allows for a fluent and efficient transfer of strength to produce sound without being inhibited by an overly high or low wrist, elbow, or shoulder. It also prevents the fingers, hands, or arms from working in isolation, which causes imbalance in the body and automatically tightens up other areas.

Piano playing presents specific problems, because it must coordinate human physiognomy with the topology of the piano keyboard. The piano keyboard is arranged with the white keys evenly distributed on one level, and the black keys slightly higher, and placed inward. Human fingers are not only uneven in length, but also vary from one person to another. Just as each person's physiognomy is fixed, so is the piano keyboard; and the challenge is to make them compatible in a way that we can achieve the "healthy virtuosity" we all seek. Many techniques of the Taubman Approach are designed to meet this challenge, working for a harmonious relationship between player and instrument, and thus preventing injury.

The most frequently taught concept in a Taubman lesson is Rotation. It is a cooperative application, made possible when the entire arm and hand are aligned and swing together as one unit. There are two kinds of rotation, single and double. The single rotation refers to a single, one-time, rotary motion. It is when the hand rotates in one direction one time, then turns in the opposite direction because of the direction of the musical line. Double rotation consists of two consecutive rotary actions in opposite directions; the first acts as a preparatory rotation to prepare for the next rotation, and the second one is the actual execution, which produces the sound. A double rotation is generally used when the notes are both descending or ascending. If we use the $\mathrm{C}$ major scale as an example:

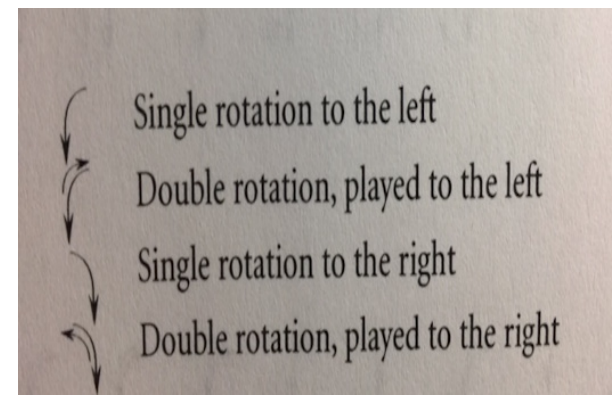

(a)

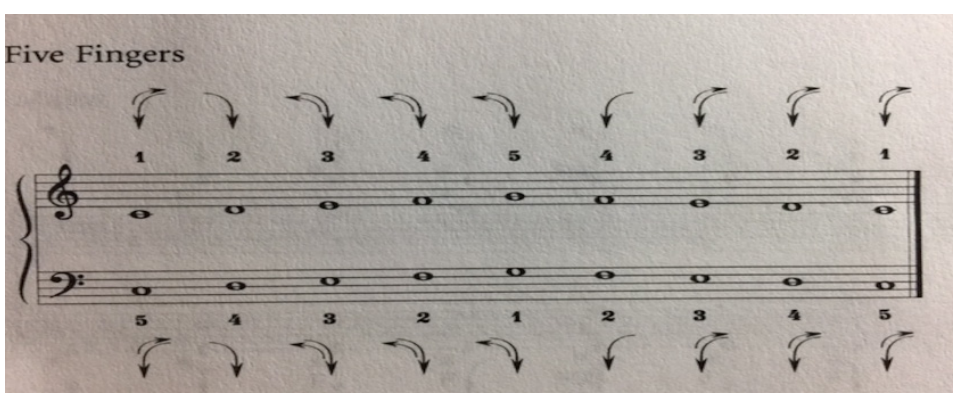

(b)

Figure 12. Score example handout from the Golandsky Summer Symposium

A double rotation will break the unit, and the fingers need to stay on the note before the next action takes place. The entire process must look simple and be done without extraneous movement. The correct rotation can prevent stretching (fingers and arm going in opposite directions) or finger isolation.

The next most common Taubman technique is In and Out. This allows the hands to cope with the direction of the music as well as the topology of the keyboard. When the music is scattered irregularly on both black and white keys, a choreographed plan for the direction of the fingers is needed, because the black keys are played by the hands moving forward towards the fallboard, and the white keys are played by the hand moving outward from the fallboard. The in and out allows for all the fingers to feel the same length, without curling or twisting to cause potential injuries. Again, using the 
C major scale as an example:

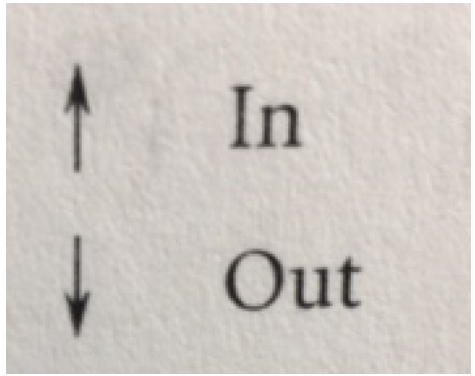

(a)

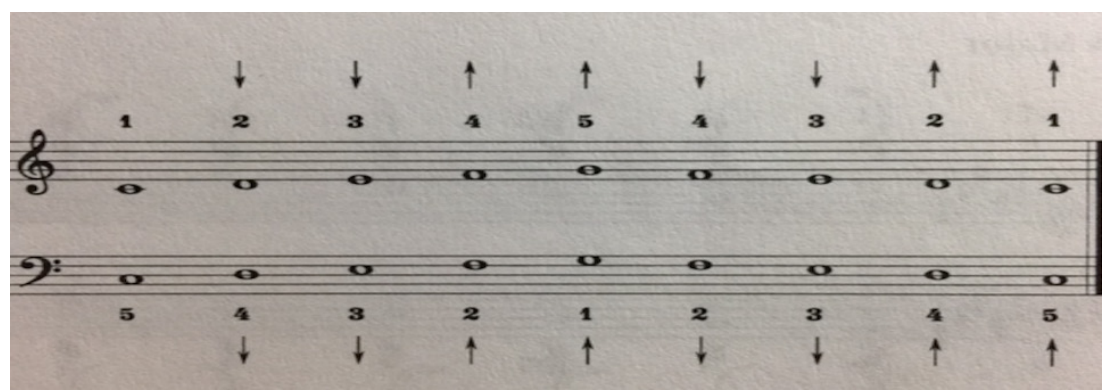

(b)

Figure 13. Score example handout from the Golandsky Summer Symposium

Attentiveness to both rotation and in and out while playing are two of the most important aspects of the Taubman Approach.

Another Taubman technique is Walking Hand and Arm. This technique can effectively minimize distance between notes. Especially when playing passages with large leaps, the walking hand and arm can effectively prevent fingers from stretching. It is a movement that requires the hand and forearm to be aligned and moving in the same direction. However, instead of moving disjointedly as the music proceeds, both the hand and arm are actively "walking" based on the direction of musical phrases. When the finger plays down, adjust the hand and forearm to make them aligned. Also, make the same adjustment when the next finger lifts to free the entire apparatus of the forearm/hand/finger unit for swinging across particularly in skips. Every lifting or walking creates space and time in between movements to allow for an adjustment, which gives freedom to coordinate for a better quality of sound.

Furthermore, Taubman developed effective ways to play Octaves. The first thing to keep in mind is to avoid using fingerings other than 1 and 5 to play an octave or a passage of octaves in order to avoid stretching or twisting, while maintaining a good alignment. Edna Golandsky, the director of the Golandsky Institute and a notable student of Dorothy Taubman, described the right way of playing octaves as "releasing the forearm into the desired finger," first little by little, until it feels light, free and stable. In the meantime, the wrist and forearm should be placed higher than playing single notes to allow bigger space for movements and adjustments.

Additionally, Taubman asked that there be no preparation before the movement, and it is better to get rid of the early engaging of the next action, eliminating over-anticipation while playing. The best sound is one made by natural arm weight, and it is reflected in the music. In a Taubman lesson, the student always hears sentences, such as, "Let the keyboard open your palm up." "Let the natural weight of your arm make the sound." "Let the piano come to you." "The natural weight makes enough sound, and it is beautiful!" Such descriptions make the performing experience enjoyable because when there is no pressure or force, the body feels free.

\subsubsection{The unique features \\ 3.2.2.1 The optimal seating}

When at the piano, students are asked to seek a balanced seating. The hip occupies only the front half of the bench, fingers lightly rest on the keyboard. The torso should feel up and forward and can move forward or backward based on whether or not the hands are at the inner or outer parts on the piano.

The correct seating height is when the student's elbow is well-aligned with the surface level of the white keys. The height of the bench, or the distance between the piano and the student, must be tailored based on his/her specific physiognomy. For example, if the upper arm is short, the seat must be adjusted low to be level with the surface of the keys. Conversely, when the upper arm is long, the bench must be adjusted high to allow the elbow to be aligned with the surface. If students are sitting too high, a "feeling of hovering" will arise, thus taking away the control from the hand and body. When the upper body is hovering, the weight goes to the wrist and makes the wrist drop, thus breaking the fingerhand-arm unit. As a result, the fingers grip the keys and can cause pain and injury to the wrist and forearm as tension gets accumulated. Moreover, when "hovering," the shoulders lift to gain control, and the result will likely always be pain and injury in this area. When sitting too low, the weight goes to the elbow, making the wrist rise up to support finger motion. The correct seating height should be able to "allow all the parts right there and available."

\subsubsection{The optimal hand position}

After the fingers, wrist, forearm, and the upper arm are well-aligned, an ideal hand position is the only part left to 
complete the hand structure. The optimal hand position of the Taubman Approach displays a neutral shape of the hand. The fingers are naturally dropped from the metacarpal-phalangeal joints, while the knuckles retain their natural curves (as if holding a golf ball). It feels like the hands are just resting and maintaining a light contact with the keyboard. In her dissertation, Milanovic states that a strong hand arch is not recommended in the Taubman Approach, because it "distorts the hand, limits finger movement, and causes tension and/or pain." Furthermore, finger-strength is not to be achieved by exercising. Thus, exercises for individual finger strength can destroy the natural structure of the hand, which causes muscles to pull against each other, creating fatigue, pain, and injury. Indeed, finger-power and independence can be properly cultivated through the support of the arm. In the Taubman Approach, the forearm plays an important role in supporting the finger movements. It is considered the "life" of pianists.

\subsubsection{The role of the forearm}

In the Taubman Approach, none of the playing apparatus should act alone without the support of other body parts. However, among all of them, the forearm plays a specifically important role to initiate the activity.

The forearm's major duties are reflected in every aspect of piano playing. In the Taubman Approach, tone production is made mainly by weight transmitted from the forearm.

As mentioned previously, with a successful alignment of the hand, pianists achieve an optimal hand position. To get a better sense of the forearm's capabilities and find out the reason why Taubman emphasizes the forearm's responsibility for sound production, it is necessary to show the anatomy of the forearm in order to understand its biomechanics.

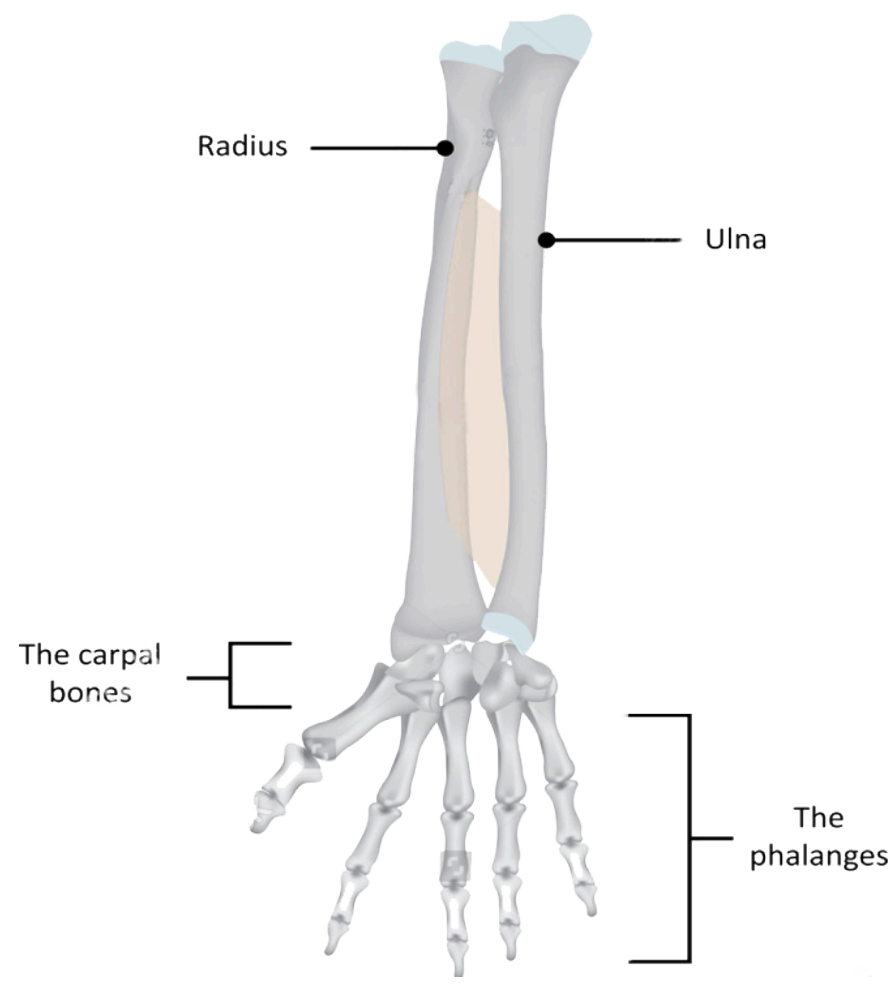

Figure 14. Forearm and hand bones

The forearm has two major bones, the radius and the ulna. They appear on each side of the forearm: the radius is closer to the thumb, and the ulna is closer to the fifth finger. When the palm is faced-down, the forearm bones display an " $\mathrm{X}$ " shape. When the palm is faced up, the two bones are parallel. To use the right hand as an example: when the hand naturally hangs at the side of the body, the palm automatically faces the thigh. When pianists use their hands to play the piano, there is always a tendency for them to turn outward due to the body's natural construction. In order to play and keep the balance during playing, Taubman taught students to coordinate with, instead of going against, their body nature, and using rotation to assist the hand to act in the most capable way.

\subsubsection{Rotation in relationship with the forearm}

As previously mentioned, rotation is considered as one of the most fundamental techniques in the Taubman Approach. It facilitates the fingers to move from note to note, first bringing the forearm to the desired spot, and then transmitting arm weight to the fingers for a key descent. A successful rotation requires all the parts of the playing apparatus to work 
synchronously; an optimal hand-alignment makes this easier.

"Listen, honey, I could stick a gun to your head, and you'd still rotate. Let it go!" said by Taubman once in a lesson. It is necessary to note that in the Taubman Approach the rotation is done only when all of the anatomical components rotate in the same direction at the same time. When rotating, the fingers no longer lift highly from the metacarpal-phalangeal joints individually (as advocated by earlier schools of technique), but all act as a unit; Taubman considered finger individualization one of the dangerous factors for pianists' hand injuries.

\subsubsection{The thumb in relationship with the forearm/rotational movement}

In Taubman's theory, finger isolation is always prohibited in every case. To prevent the thumb from moving in isolation, it needs the support of the forearm when rotating. While the other fingers are moving with the forearm, the thumb inevitably moves in the same direction, less actively, but more passively.

\subsubsection{Use of minimization and mid-Range movement}

"Approaching the extremes of motion creates tension and loss of efficacy." Taubman especially advocates the mid-range movement during playing. In the Taubman Approach, all techniques introduced are finalized in a mid-range movement, nothing is too big or small. It is within a range where there is space for the hand to comfortably move and adjust itself.

Minimization is a good way to help achieve this goal. The rotation movement may be used as an example to illustrate how to transfer from a big rotary movement into a smaller one. At the beginning of the training process, especially for rotation, it is suggested to exaggerate this movement in order to learn a new sensory motion while overcoming the old habits. Since many of the old habits could be wrong and injurious, the retraining process forms a crucial step for an effective cure. Not until all of the techniques are well-integrated into a coordinated whole can the students proceed to minimization, internalizing these techniques into smaller sensations inside the forearm and play everything at the required tempo.

Minimization facilitates the hands to use the minimal effort for greater power; it is the ultimate goal to which all somatic approaches aim.

\subsection{Barbara Lister-Sink: Freeing the Caged Bird}

\subsubsection{The overview}

Barbara Lister-Sink's Freeing the Caged Bird theory is a well-coordinated, injury-preventive piano technique, which aims at cultivating kinesthetic awareness, or having a sense of body position and muscle movement for example, to prevent pianists' hand injuries. In her article, "Rethinking Technique," Lister-Sink mentions the dilemma that the piano community faces:

Although the centuries-old good technique of good coordination and efficient body use exists, something prevents it from widespread and universal acceptance. Pedagogical systems that teach this technique have come and gone while teachers and students continue to grapple with partial or faulty knowledge, discomfort, pain and injury.

Observing the waste of great pianistic talent and waning interest in proper coordination, Lister-Sink sought to introduce somatic techniques into current piano teaching.

In Freeing the Caged Bird, Lister-Sink divides her teaching into two sequential parts; the first aims at enhancing kinesthetic awareness, and the second is to develop body coordination in piano playing.

(1) Kinesthetic awareness retraining of the whole-body ("neuromuscular programming").

Good coordination at the piano results from a good coordination of the entire body. Strongly allied with the Alexander Technique, Lister-Sink integrates the basic principles of the Alexander Technique and uses them to improve students' kinesthetic awareness prior to their learning tone production. The Alexander Technique was created by Frederick Matthias Alexander, who developed a technique originated to alleviate his breathing problems and hoarseness during public speaking to enable his return to his beloved acting stage. This technique has an abundant reservoir of resources to help singers, vocal performers, and all others whose careers are closely related to the use of body and/or voice.

In contrast to whole-body approaches, such as the Feldenkrais Method, the Alexander Technique commences directly with body movement by diagnosing students' responses (the problem-causing habit) to a stimulus. By kinesthetically sensing, redirecting, and then eliminating the faulty habits, students learn to make better use of their bodies and achieve coordination.

(2) For the second part of Lister-Sink's method, a teacher's hands-on guidance is especially important. It begins with the exercise of the "Basic Stroke," which has four components:

1) An easy, efficient lift of the forearm 
Lift and drop the forearms of the left and right hands alternatively, the upper arms hang naturally at the side; the wrists and fingers are completely relaxed during the movements; the purpose of the exercise is to eliminate tension in the hand and arm and let the same sensation learned from the previous whole-body coordination infuse into the playing apparatus during these slow and gentle movements.

2) Freefall of the forearm

When the students' hands are relaxed, resting on their laps, the teacher picks up the forearm to check if there is any unnecessary tension within the wrist, hand, and lets the whole arm fall naturally; pianists then perform the movements by themselves and try to maintain the same feeling as when the teacher is checking. Students compare their own movements with the teacher's guided movements to better remember the correct sensation, and combine it with the practice of the "easy and efficient lift of the forearm" to form a completely relaxed lift and fall. This process is then taken to the keyboard; the new sensation is solidified by many repetitions under the close supervision of the teacher.

3) Achieving optimal bone alignment and muscle contraction at the moment of impact

Let the arm hang at the side of the body, so that the hand displays the most natural shape, then move to the piano. The teacher then lifts the forearm under the wrist and sets up an arch between the hand and arm (this is the optimal alignment to transmit weight to the key bed). The students feel how the support of the arm weight is transferred from torso to the thigh, especially the muscle contraction at the moment of impact. Then, shift the weight back from thigh to torso and feel the sequence of muscle contractions during the weight transfer.

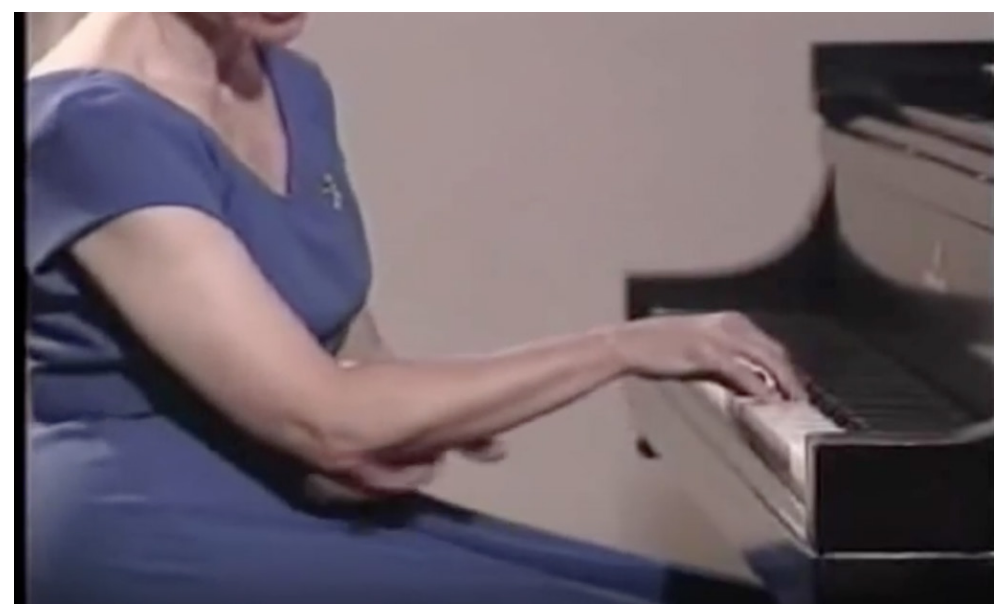

Figure 15. Freeing the Caged Bird

4) Instantaneous release of unnecessary arm tension

Release the tension completely between the muscle contractions because "any real muscle effort after the moment of impact is wasted effort." First practice on the thigh, watching closely to avoid any accumulation of tension, and then transfer it to the piano.

5) To combine the four components of the "Basic Stroke," the teacher first demonstrates the entire set at the piano. When the student begins to combine the four components together, it is most important for the teacher to check for accumulations of tension; even a little tension in hand and arm is prohibited in the Freeing the Caged Bird method.

After mastering using one basic stroke per one note, the students can proceed to play two notes, then three, four, and eventually longer musical phrases using only one basic stroke. One thing to keep in mind is the importance of maintaining a full kinesthetic awareness in all movements, including the arch, the lift, and the fall. All of these must be done without tension.

\subsubsection{The unique features}

\subsubsection{The instantaneous release}

Lister-Sink advocates using arm weight for tone production and opposes finger individualization because it can lead to injuries. However, Lister-Sink also believes that a necessary amount of muscle tension is needed at the moment of impact in order to stabilize the joints. To prevent tension from accumulating, and thus causing fatigue in playing, the instantaneous release is applied.

A stable hand structure is required during the release. This structure plays an important role in facilitating a smooth transfer of weight by aligning the hand to support the finger movements. It prevents each part of the playing apparatus from acting in isolation while allowing for stability and power to occur during performance. By proper application of the 
Basic Stroke, one can learn to release muscle tension soon after sensing its accumulation during playing. This process of "take and give" effectively refreshes the muscle, so that students can play without fatigue.

Although Lister-Sink does not mention the rotary movement in her DVD, the instantaneous release of muscle tension is indeed considered a calibration technique. It provides students with a chance to breathe and readjust during performance, so that the muscles do not accumulate tension during playing.

In her DVD Freeing the Caged Bird, Lister-Sink uses Chopin's Etude Op. 10 No. 8 (see figure 3.31) as an example to demonstrate the instantaneous release in fast note playing.

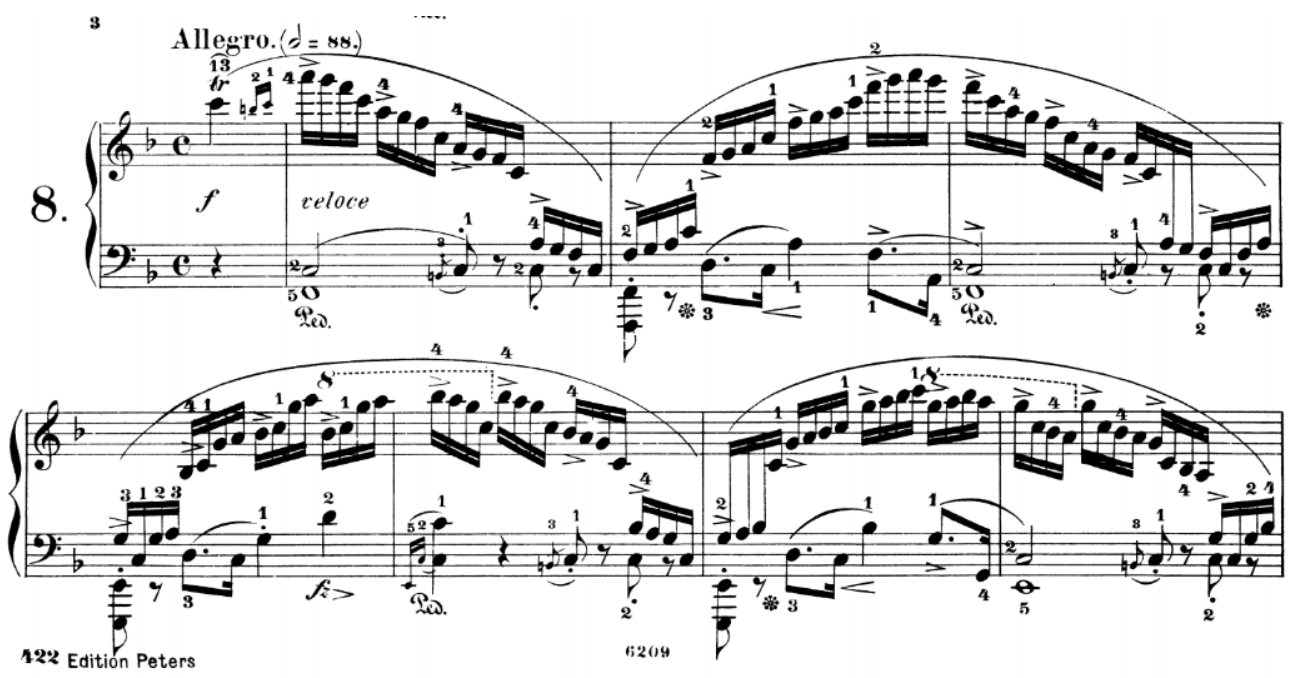

Figure 16. Chopin Etude Op.10 No.8; mm.1-7

In this exercise, she divides the right hand sixteenth notes into fragments of quadruplets. Between every two fragments, there is a pause placed at the end of the first fragment and the beginning of the new one. During these silences, the exaggerated space and time being created in the middle of a running passage give students an opportunity to also maximize the level of muscle release while regaining awareness and re-calibrating. By restoring awareness effectively between fragments, pianists also regain control of the body and the music. After all the musical fragments have been well integrated through the Basic Stroke, students apply the same principle into a longer phrase. Eventually, when they link all the fragments together, students can play the passage in its entirety with ease and fluidity.

\subsubsection{Basic stroke for neuromuscular reprograming}

One of the decisive factors in achieving body/mind coordination is to eliminate the old habits and replace them with new ones. Students must first reprogram the brain and then combine it with the playing apparatus, which includes the fingers, hand, and arm.

As mentioned previously, Lister-Sink makes concurrent use of the Alexander Technique for developing whole body awareness. To combine it with the playing apparatus, Lister-Sink suggests using the Basic Stroke along with the five-finger pattern to solidify the sensation while mastering the instantaneous release within this exercise (see Figure 17).
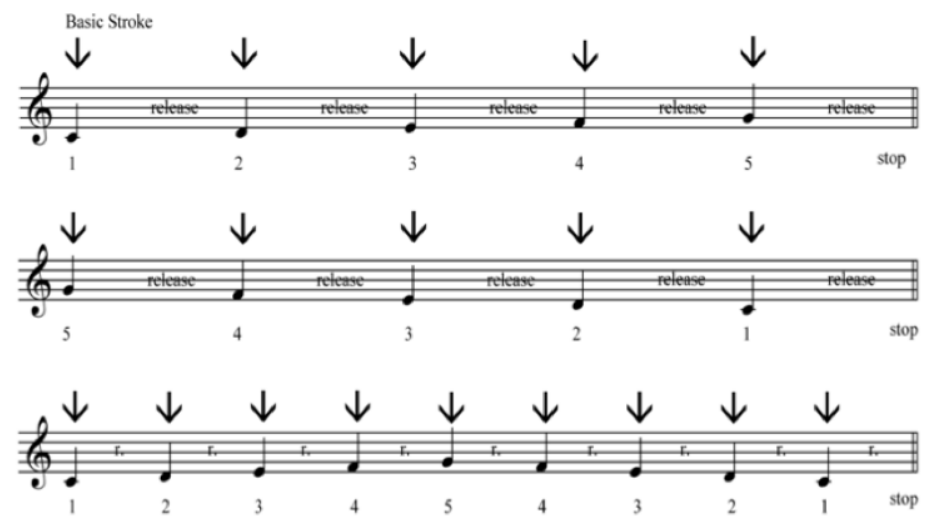

Figure 17. The five-finger pattern of the Basic Stroke in Freeing the Caged Bird 
Each arrow signals the start of a Basic Stroke, and it denotes one note per each stroke. The release between every two notes marks the end of the stroke and allows for a long pause to permit enough time to release any accumulated tension in the hand. An effective calibration is achieved between every two strokes. It gives an opportunity to invite a new sensation into the playing mechanism, thus developing a new habit to replace the old one. If one can master this fundamental coordination, he/she will be able to progress playing more complex phrases.

\subsubsection{Multiple notes in one movement/basic stroke}

After students have mastered the coordination of one note per Basic Stroke, they can proceed to applying the same sensation to more complex exercises, such as playing more than one note within one stroke. The stroke, which includes more than one note, is an expanded version of the one-note-per-stroke. Since more finger activity is involved, it requires better coordination and muscle release to avoid tension. It is played the same way as playing the one-note-per-stroke. Students must follow the four-step Basic Stroke principle, without adding excessive motion to it. Each movement starts with an easy lift and ends with a free fall. The maximum number of notes allowed in-between is five, so the pianist can retain awareness effectively in this short and simple five-finger pattern. It is worth mentioning that students must maintain an optimal hand alignment the entire time because it supports the hands and brings all parts of the playing apparatus into a unified whole.

\subsubsection{Basic stroke in advanced repertoire}

Before proceeding to play a more challenging piece, Lister-Sink first recommends less complicated repertoire for students to try with the Basic Stroke. In a sequential process, it first begins with a two-note per stroke piece, then the three, four, and five-note-per-stroke pieces. Students must successfully grasp the Basic Stroke in pieces at each stage before proceeding to more advanced repertoire.

When students approach a challenging piece, the long and complex passages are broken into smaller fragments using the Basic Stroke. This time students must first locate where each stroke starts and ends and establish the best coordination for both body and music. In most cases, the decisions are made based on "phrase length, tempo, frequency of rhythmic pulses or accents, etc." Sometimes, "personal taste can also influence the placement of the Basic Stroke."

\section{Comparison}

\subsection{Three methods - one common denominator}

There are many differences among the three somatic approaches in their methods for sound production, weight transfer, finger activity, and so on. Yet, they all share a common denominator: the natural alignment of the hand. Usually, an optimal hand alignment is the basic way to natural, unforced movements. Fraser advocates a strong hand structure and emphasizes the hands' innate structural power to make sound; an integrated structure is the crucial component for achieving this power. A substantial arch (the natural shape) of the hand must be present at all times, which is made possible by the hands' metacarpal-phalangeal joints standing like a mountain top. Here, fingers need to be activated to transfer a stable hand structure into movements in order to produce sound. Activities such as grasping, thumb push-ups, legato and many other exercises form the core of ideas of his The Craft of Piano Playing. Fraser's method supports individual fingers' natural power. Therefore, stretching, twisting, and many other activities, which are considered detrimental in the other two approaches, are not potential risks in Fraser's method.

The Taubman Approach also relies on the hands' natural alignment for effective hand activity, but the difference is that the sound is produced from weight transferring from the forearm to the fingers. Taubman supports a mid-range movement of the hand and less active movements of the fingers. In most cases, the forearm plays an active role to compensate for less active fingers. Rotation is one of the most fundamental techniques to facilitate finger activity. Other techniques, such as in and out and walking hand and arm, are designed to support the hands' specific movements in order to prevent its natural alignment from breaking. The Taubman Approach caters to the construction of both the hand and piano; thus, the fingers' power and independence develop from an organic relationship with the mechanics of the piano.

Barbara Lister-Sink's Basic Stroke is considered the most fundamental technique for developing coordination in Freeing the Caged Bird. The four-step principle includes an easy and efficient lift and free fall, the instantaneous release, and an optimal skeletal alignment. The method first starts developing awareness in the whole body, and is integrated with the basic principles of the Alexander Technique. In Lister-Sink's DVD of Freeing the Caged Bird, students learn about the body mechanism and natural skeletal alignment. The objective in Lister-Sink's method is for pianists to have a tension-free playing experience, with an "instantaneous muscle release" as the most crucial step in facilitating the goal of achieving mind body coordination. Technique is solidified by dividing long phrases into smaller fragments and integrating them with 
the Basic Stroke.

\subsection{Terminology}

\subsubsection{Fraser}

In the Craft of Piano Playing, Fraser adopts the terminologies of anatomical analysis, which were inherited from the Feldenkrais Method. These terms are used to give a clear explanation of the body's skeletal structure; students absorb this information and then consciously apply it to the use of their bodies. By knowing what role each body part plays within the overall skeletal structure, students can better connect these roles to support the development of their technique.

In addition, Fraser's language also incorporates the terms strength, vigor, power, potent structure, finger activation, and so on. These terms combine with the anatomical ones to shape the overall language of The Craft of Piano Playing.

\subsubsection{Taubman}

Teachers of the Taubman Approach use a mind-body approach, integrating body movements with the motor cortex through a less scientific language. For example, Taubman used the phrase, "Let the piano open your palm up," when teaching students how to avoid stretching in playing octaves. Phrases, such as this, remind the student of: 1) less active hand movement 2) no preparatory work because it wastes energy and attention and will not produce an efficient sound. The hands should remain in their natural hand alignment at all times, to maintain the musical flow, and fluidity of the hands' movements.

Another example is, "Let your arm be flat with the floor," when teaching the proper seating posture at the piano. Taubman's language has a more vivacious tone than the other two approaches, bringing a sense of vigor to what might otherwise be monotonous. By integrating liveliness and emotion into seemingly mechanical hand movements, this approach rebuilds the connection between body and mind, so playing the piano becomes a communication between the self and the instrument.

\subsubsection{Lister-Sink}

Compared with the Taubman Approach, Freeing the Caged Bird's success is partially attributed to its hands-on instructor who closely monitors students' progress and focuses on intervention to confront harmful habits. For example, in her DVD of Freeing the Caged Bird, Lister-Sink continuously checks for improvements by lifting the students' arms to see if they had successfully released the tension. If the hand and arms collapse naturally, the tension has been released; if not, tension is still present.

Lister-Sink's four easy-to-do movements of the Basic Stoke uses simple and comprehensible language (see page 33). Students can easily understand the concepts during the hands-on lesson while interacting with a teacher's instruction.

\subsection{Does technique improve from exercises?}

Among all three approaches, only the Taubman Approach does not agree that exercises can develop technique. Most of her finger movements emphasize the hands' inert motion. The Craft of Piano Playing and Freeing the Caged Bird, however, contain a good amount of exercises either away from or at the piano. Most of the exercises in Fraser's method are for promoting finger power. Lister-Sink's exercises are designed to develop body awareness through kinesthetic learning (integrated with the Alexander Technique), and then cultivate the playing apparatus to use the new kinesthetic pattern. More specific exercises are also designed to consolidate the application of the Basic Stroke, such as the five-finger pattern, or dividing long phrases into fragments for developing coordination and fluency at the piano.

While the Taubman Approach does not rely on exercises to improve technique, it is noted that students must develop the fingers' ability to stand and move on the keys (the basic techniques) before approaching the method.

It is worth mentioning that the Taubman Approach and Freeing the Caged Bird are injury-preventive approaches, but Fraser's Craft of Piano Playing was not originally intended as such. Fraser notes that "minimizing the risk of injury should not be the goal of technique, but it certainly can be a welcome byproduct, because as it turns out, the most effective way to maximize orchestral color is also usually [the] healthiest!"

\subsection{On relaxation}

A complete relaxation in piano technique is discouraged by all three approaches.

For Taubman, a total relaxation generates a heaviness, which limits the range of movement and impedes the speed. During the hands' active motions, it is important to have a stable and firm fulcrum point. The fulcrum point here is the forearm, which plays an important role supporting finger activities behind the hand, while giving a restraint for a limited range of these movements. Additionally, it provides hands with a sense of security.

Fraser said that "life without movement is unthinkable, and just as any other movement, pianistic movement comes 
from activity." Movement and relaxation balance each other; lack of muscle movement is compensated by excessive brain activity. The result is an uncoordinated mind and body during piano playing, leading to hand injuries and unpleasant performing experiences.

Lister-Sink approaches the problems of accumulated tension from a slightly different angle, instructing students to "relax the arm muscles completely to a state of release to which the pianist must always return." She considers accumulated tension as the primary cause for hand injuries and thus advocates a system of tension-free piano playing through instantaneous release. This split-second of muscle relaxation of the instantaneous release is a continuous, on-going process since tension is accumulated as long as the muscle is being used. When muscles contract and do not have proper release, toxicity in the muscles builds up as a result of the accumulated tension; the muscles aren't properly oxygenated, which in turn causes damage. A successful cultivation of kinesthetic awareness through exercises, for the purpose of accurately sensing the accumulation of tension and then releasing it immediately, are the merits of this approach.

\subsection{Muscle co-contraction}

Muscle co-contraction results from two or more opposing muscle groups that contract simultaneously. It causes muscles to pull against each other and is considered one of the major predisposing factors for hand injuries. Many injurypreventive approaches strongly oppose muscle co-contraction, especially the Taubman Approach. However, the rest agrees that an appropriate amount of muscle co-contraction is needed to fixate the joints for sound production. Lister-Sink is one of them and believes that a necessary amount of muscle co-contraction is needed at the moment of impact. Nevertheless, a release of tension must follow immediately after the sound has been made to prevent it from accumulating.

Fraser also goes for the latter point, and advocates a healthy muscle co-contraction because it plays "a crucial role in fine-tuning the degree of stability offered by any given point." An optimal alignment of the hand is considered the tool needed to balance and measure the right amount of co-contraction. There should be no feeling of stabilization, but rather of efficiency and fluidity of movements.

\subsection{Finger independence}

All three approaches agree on finger independence for power and effective sound. However, their understanding of, and the way to achieve this independence, is different. Fraser believes in each finger's individual ability to make sound and designed exercises to strengthen the fingers' innate power. He believes that only through finger activation can a stable and potent hand structure be brought into play. Conversely, the Taubman Approach does not welcome any kind of finger individualization, but nevertheless acknowledges finger independence as needed for power. Finger power here results from the synchronized work of all parts of the playing apparatus working together, facilitated by techniques such as rotation, in and out, walking hand and arm, etc. Freeing the Caged Bird stands somewhere in the middle. The Basic Stroke contains light movements for coordination, such as an easy lift and free fall, but it also advocates muscle co-contraction followed by an immediate release of tension.

\subsection{Sound production}

Both Taubman and Lister-Sink's methods work with gravity and let the weight be transmitted from the arm to fingers. By contrast, Fraser discourages students from using arm weight for sound production. Rather, he relies on the students' innate ability (fingers' natural power) to produce sound, not engaging gravity (an uncontrolled force) into his method. He uses an example of letting the hands play under the table (palm facing up) eliminating the reliance on gravity and producing the sound through finger activity. Certain arm-weight schools encourage total muscle relaxation as the basis for sound production, but both the Taubman Approach (TA) and Freeing the Caged Bird state that a well-aligned hand structure is the foundation for transmitting arm weight. All finger activities must be done under this alignment; they do not lean on either side of the total relaxation, nor active finger activity alone, for sound production.

\subsection{Elimination of harmful habits}

All three approaches agree on the fact that most hand injuries occur due to the wrong way of using the body.

Freeing the Caged Bird (FCB) is deeply influenced by the Alexander Technique; this somatic, whole-body approach aims at improving one's use of the body through solving problems by eliminating incorrect, habitual patterns. Oppositely, Lister-Sink and Taubman both consider uncoordinated movements as harmful. Such factors as the excessive key pressure and motion (FCB) or key-bedding (TA) are the result of an unbalanced hand. High and curved fingers (FCB), or finger curling and individualization (TA), occur due to overly-active finger-actions and the lack of optimal hand alignment for supporting finger activity. Raised or tightened shoulders (FCB) are relative to a low seating posture. Supporting weight on the lower wrist (FCB \& TA) is attributed to irregular hand alignment, or too-low seat height. A too-low wrist inhibits 
weight transference from the arm and generates fatigue and pain. Lastly, total hand relaxation is considered harmful due to the heaviness and tension accumulated when there is no stabilizing factor (i.e., hand alignment) to support hand movements.

Fraser's The Craft of Piano Playing does not mention much about eliminating harmful habits, but rather focuses on obtaining an accurate, overall skeletal alignment, using only the exact amount of effort needed for purposeful and effective playing.

\section{Conclusion}

This study has sought to explore three somatic approaches to piano playing and evaluate their effectiveness for assisting pianists in avoiding playing-related injuries, and for developing a healthy approach to piano performance through an understanding of the biomechanics of movement as applied to piano playing. Each technique has its advantages and disadvantages, and each pianist must evaluate the value of each according to his or her own personal needs.

Fraser's The Craft of Piano Playing is built on the principles of the Feldenkrais Technique. Since Feldenkrais was a martial arts practitioner, he based his method on the martial arts' training for coordination of mind and body for efficient movement and purposeful attack. While this makes for a positive physical approach to piano playing, it may or may not be effective in linking movement with the music itself. The strength of The Craft of Piano Playing lies in its awareness of human anatomy and proper use thereof, the knowledge of which is beneficial to pianists. It should be observed however that concepts such as finger individualization, thumb push-ups are considered detrimental by other somatic approaches; and if not used properly, they could result in hand injuries.

Lister-Sink's Freeing the Caged Bird, maintains that all the techniques grow from a successful mastering of the Basic Stroke, and students can then apply and expand it to a larger extent, integrating it into the movements needed to realize music making, where the piano directly serves the music. Lister-Sink has very successfully implemented the Alexander Technique, which by itself does not have a specific application in piano playing and tailors its use to compliment the needs of the pianist. In her DVD, we observe a great deal of Lister-Sink's own performances with many pieces demonstrated in their entirety. It is noted here, however, that the demonstrations do not in themselves offer explanations or details about how the fluidity of movements and ease in playing are being achieved, yet the demonstrations fully show the positive effects of the technique.

Highly recommended here is the Taubman Approach, particularly for those pianists who are seeking a cure for playing-related hand injuries. Not only does the Taubman Approach have the support of many pianists and teachers, it has also been shown to successfully cure many types of hand injuries among pianists. More than merely a remedy, the Taubman Approach is also noted for teaching techniques to enhance pianists' virtuosity. It contains the knowledge to systematically educate students in using these techniques to serve the music, by teaching them ways of shaping, grouping, or proper fingering based on what is written in the score, and what best fits the composer's intentions. Most importantly, all of this is accomplished by developing unity of mind and body. The Taubman Approach is a fully developed, comprehensive approach, which offers solutions for many problems a pianist may encounter.

The value of this study lies in making pianists aware of the need for knowledge of their own playing mechanism, the biomechanics of their bodies, and how to develop their playing technique in a healthy way. It is hoped that this examination of three somatic approaches to piano playing will encourage pianists, particularly those with playing-related injuries, to find a somatic approach that works best for them and also encourage further development of somatic techniques for future generations of pianists.

\section{References}

[1] Eric Sams. Schumann's Hand Injury. The Musical Times. 1971; 112(1546): 1156.

[2] Leon Fleisher: "My life fell apart...". Independent.co.uk, http://www.independent.co.uk/arts-entertainment/music/features/leon-fleisher-my-life-fell-apart-1984408.html, last modified May 29, 2010.

[3] What is Somatics. Generative Somatics: Somatic Transformation and Social Justice, http://www.generativesomatics. org/content/what-somatics, accessed October 18, 2017.

[4] Thomas Hanna. What is Somatics? https://somatics.org/library/htl-wis1, Somatics. org, accessed November 17, 2017.

[5] Helmut Milz M.D. A Conversation with Thomas Hanna, Ph.D. Somatics: Magazine-Journal of the Bodily Arts and Sciences. 1991; 8(2): 50-56. 
[6] Thomas Hanna. Somatics: Reawakening the Mind's Control of Movement, Flexibility, and Health. Boston: Da Capo Press; 2004.

[7] Moshé Feldenkrais. The Potent Self: A Guide to Spontaneity. San Francisco: Harper \& Row; 1985.

[8] Hans Seyle. The Stress of Life. New York: McGraw Hill Education; 1956.

[9] Alan Fraser. The Long Road to a New Piano Technique. Alanfraser.net, http://alanfraser.net/about/bio/the-long-roadto-a-new-piano-technique/, accessed October 18, 2017.

[10] Walter Isaacson. The Science Behind Mona Lisa's Smile. theatlantic.com, https://www.theatlantic.com/magazine/archive/2017/11/leonardo-da-vinci-mona-lisa-smile/540636/, accessed November 17, 2017.

[11] Ken Keuffel. Easing the Pain of the Piano Player. Winston-Salem Journal. http://www.journalnow.com/relishnow/article_acc3e3d1-ea49-560e-841b-8d3cedb2802b.html, last modified May 18, 2008.

[12] Mayumi Osada. (2009) The Lister-Sink Method: A Holistic Approach to Injury-Preventive Piano Technique. DMA dissertation. The University of North Carolina, Greensboro.

[13] Moshé Feldenkrais. Higher Judo: Groundwork. London: Frederick Warne \& Co. Ltd; 1952.

[14] Awareness Through Movement Classes. Feldenkrais.com, https://feldenkrais.com/awareness-movement-atm-classes/ and Functional Integration Sessions. Feldenkrais.com. https://feldenkrais.com/functional-integration-fi-sessions/, accessed October 18, 2017.

[15] Part 6: Alan Fraser Piano Technique Master Class Lins Austria. YouTube video, posted by Craft of Piano Method on Aug. 8, 2010, https://www.youtube.com/watch?v=1B5mZL8Kp4c.

[16] Alan Fraser. The Craft of Piano Playing: A New Approach to Piano Technique, Second Edition. Lanham, MD: Scarecrow Press, INC.; 2011.

[17] Grasping's Amazing Power in Piano Technique-from Alan Fraser's The Craft of Piano Playing. YouTube video, posted by Craft of Piano Method on Aug. 8, 2010, https://www.youtube.com/watch?v=DMYyesdF4Jo.

[18] Therese Milanovic. The Taubman Approach to Piano Technique. Thepianoteacher.com.au, http://thepianoteacher.com. au/articles/the-taubman-approach-to-piano-technique/, last modified May 6, 2014,

[19] Choreography of the Hands: The Work of Dorothy Taubman. YouTube video, posted by David Szabo on March 5 , 2015, https://www.youtube.com/watch?v=47w_6IKHA1M.

[20] Therese Milanovic. (2011) Learning and Teaching Healthy Piano Technique: Training as an Instructor in the Taubman Approach. Ph.D dissertation. Queensland Conservatorium, Griffith University.

[21] Correct Seat Height — an excerpt from the Taubman 10 DVD Series. YouTube Video, posted by The Golandsky Institute on November 3, 2008, https:/www.youtube.com/watch?v=H_v5VdEDrHs

[22] Edna Golandsky: Playing Scales with the Taubman Approach and the Process of Minimizing. YouTube video, posted by Edna Golandsky on Feb.16, 2013, https:/www.youtube.com/watch?v=eevJ937ikGI\&list=PLVy1M_cVhLxtKm_ s4dajKMzPrdDgB1A7B\&index $=2$.

[23] Therese Milanovic. Clarifying some misunderstandings about rotation. Therese Milanovic (blog), November 12 , 2014, http://www.theresemilanovic.com/blog/706/.

[24] Therese Milanovic. Learning and Teaching Healthy Piano Technique. LAP LAMBERT Academic Publishing; 2014.

[25] Barbara Lister-Sink. Rethinking Technique. Lister-Sinkinstitute.org, https://www.lister-sinkinstitute.org/assets/RethinkingTechnique.pdf, accessed November 17, 2017.

[26] Barbara Lister-Sink's Feeing the Caged Bird: Muscle Tension. YouTube video, posted by The Lister-Sink Institute on January 9, 2009, https://www.youtube.com/watch?v=7cVLmQE7_Vs\&index=2\&list=PLbN4aHgCbDOiFm t21maRM1NfZNaOT7B7.

[27] Basic Stroke. YouTube video, posted by Александр Коскин on December 26, 2010. https://www.youtube.com/ watch? $=$ OjSWu8ZADzI.

[28] Alan Fraser. The Downside of Relaxation in Piano Technique. Alanfraser.net, http://alanfraser.net/2011/04/the-downside-of-relaxation-in-piano-technique/, accessed October 18, 2017.

[29] Alan Fraser. Honing the Pianistic Self-Image. Novi Sad: Maple Grove Music Productions; 2010.

[30] Lister-Sink, Barbara. Freeing the Caged Bird. DVD. United States: WINGSOUND International. November 2005.

[31] Barbara Lister-Sink's Freeing the Caged Bird: Muscle Tension. YouTube video, posted by The Lister-Sink Institute on January 9, 2009. https://www.youtube.com/watch?v=7cVLmQE7_Vs\&index=2\&list=PLbN4aHgCbDOiFm t21maRM1NfZNaOT7B7.

[32] Bishop Beata, Gerson Charlotte. Healing the Gerson Way, Defeating Cancer and Other Chronic Diseases. New Edition. Carmel, CA: Gerson Health Media; 2010.

[33] Feldenkrais, Moshé. Awareness through Movement. Illustrated Edition. San Francisco: Harper \& Row; 1972. 